\title{
A Study on the Applicability of $\mathrm{NiFe}_{2} \mathrm{O}_{4}$ Nanoparticles as the Basis of Catalysts for the Purification of Aqueous Media from Pollutants
}

\author{
Artem L. Kozlovskiy ${ }^{1,2}, * \mathbb{D}$, Anna S. Zagrebova ${ }^{2}$, Rauan Sh. Abdinov ${ }^{1}$, Inesh E. Kenzhina ${ }^{2,3,4}$ \\ and Maxim V. Zdorovets $2,5,6$ (D)
}

check for

updates

Citation: Kozlovskiy, A.L.; Zagrebova, A.S.; Abdinov, R.S.; Kenzhina, I.E.; Zdorovets, M.V. A Study on the Applicability of $\mathrm{NiFe}_{2} \mathrm{O}_{4}$ Nanoparticles as the Basis of Catalysts for the Purification of Aqueous Media from Pollutants. Catalysts 2021, 11, 1393. https:// doi.org/10.3390/catal11111393

Academic Editors: Lucia Curri and Antonio Zuorro

Received: 28 October 2021

Accepted: 15 November 2021

Published: 18 November 2021

Publisher's Note: MDPI stays neutra with regard to jurisdictional claims in published maps and institutional affiliations.

Copyright: (c) 2021 by the authors. Licensee MDPI, Basel, Switzerland. This article is an open access article distributed under the terms and conditions of the Creative Commons Attribution (CC BY) license (https:/ / creativecommons.org/licenses/by/ $4.0 /)$.
1 ASU Innovations, Kh. Dosmukhamedov Atyray University, Studenchesky Ave., Atyrau 060009, Kazakhstan; r.abdinov.dau@inbox.ru

2 Laboratory of Solid State Physics, The Institute of Nuclear Physics, Ibragimov St., Almaty 050032, Kazakhstan; azagrebova@gmail.com (A.S.Z.); kenzhina@physics.kz (I.E.K.); mzdorovets@gmail.com (M.V.Z.)

3 Scientific and Education Center Material Science and Corrosion Problems, Kazakh-British Technical University, Tole bi St., Almaty 050000, Kazakhstan

4 Institute of Experimental and Theoretical Physics, Al-Farabi Kazakh National University, Al-Farabi St. 71, Almaty 050040, Kazakhstan

5 Engineering Profile Laboratory, L.N. Gumilyov Eurasian National University, Satpayev St., Nur-Sultan 010008, Kazakhstan

6 Department of Intelligent Information Technologies, Ural Federal University, Mira Str. 19, 62000 Ekaterinburg, Russia

* Correspondence: kozlovskiy.a@inp.kz

\begin{abstract}
The aim of this work is to evaluate the application of $\mathrm{NiFe}_{2} \mathrm{O}_{4}$ nanoparticles with spinel structures as the basis of catalysts for the purification of aqueous media from pollutants such as manganese and arsenic. The interest in these catalysts is due to their ease of production and high absorption efficiency, which, together with their magnetic properties, allow the use of nanoparticles for a long time. The sol-gel method, followed by thermal annealing of the samples at different temperatures, was proposed as a method for the synthesis of spinel nanoparticles. The choice of the annealing temperature range of $200-1000{ }^{\circ} \mathrm{C}$ is caused by the possibility of estimating changes in the structural properties and the degree of nanoparticles crystallinity. During the study of structural changes in nanoparticles depending on the annealing temperature, it was found that in the temperature range of $200-800^{\circ} \mathrm{C}$, there is an ordering of structural parameters, while for samples obtained at annealing temperatures above $800^{\circ} \mathrm{C}$, there is a partial disorder caused by the agglomeration of nanoparticles with a subsequent increase in their size. According to the results of the studies on the purification of aqueous media from pollutants, it was found that the greatest absorption efficiency belongs to nanoparticles annealed at $500-700{ }^{\circ} \mathrm{C}$, with the purification efficiency of $70-85 \%$, depending on the type of pollutant. The results obtained from the use of nanoparticles as catalysts for the purification of aqueous media show great prospects for their further application on an industrial scale.
\end{abstract}

Keywords: nanoparticles; catalysts; aqueous purification; spinel; thermal annealing

\section{Introduction}

In recent years, much attention has been paid to environmentally friendly methods of producing nanostructured materials and nanoparticles, which have great prospects for use in various fields of technology, including microelectronics, biomedicine, catalytic decomposition of pollutants and dyes [1-3]. An important role in such studies is played by spinel structures with a number of unique properties that allow them to be used in a large number of different applications [4-10].

The interest in this research is due to the possibility of developing inexpensive methods for the synthesis of nanostructures both in the laboratory and on an industrial scale. Special 
interest in this field is increasingly focused on the application of magnetic nanoparticles or composites based on them as catalysts and absorbents used for water purification, decomposition of organic dyes, etc. [11,12]. The interest in this area of research is due to the need to replace expensive catalysts with cheaper ones obtained using simple synthesis methods, as well as to increase the decomposition and purification efficiency due to the transition to nanoscale objects $[13,14]$. Moreover, the use of magnetic nanostructures as a basis for catalysts enables cheaper decomposition processes, as well as free extraction of catalysts from aqueous media by magnetizing them to a magnetic surface without losing mass due to their magnetic properties [13,14].

Among the variety of magnetic nanoparticles, nanoparticles based on iron and nickel compounds with spinel structures are among the most promising [15-17]. $\mathrm{NiFe}_{2} \mathrm{O}_{4}$-type nanoparticles with spinel structures and unique magnetic, conductive properties, and a high degree of degradation resistance, compared with iron oxide nanoparticles, are increasingly used in practical applications due to their properties. Nowadays, there are quite a number of different methods for obtaining $\mathrm{NiFe}_{2} \mathrm{O}_{4}$ nanoparticles, which allow obtaining nanoparticles of different geometry and degree of crystallinity [18-24]. Among all methods, the sol-gel method can be singled out, which allows obtaining nanoparticles of monodisperse size but with a low degree of crystallinity and a large number of vacancy defects in the structure. To increase the degree of crystallinity, which plays an important role in preserving the stability of nanoparticles for long-term operation, as a rule, the thermal annealing method is used to restore the structure and annihilate the point defects. However, the use of this method to restore the structural properties, as well as to increase the degree of crystallinity, may be accompanied by phase transformations or agglomeration of nanoparticles as a result of sintering. In this connection, to understand the modes of obtaining highly ordered nanoparticles with a well-formed crystal structure, it is necessary to conduct research aimed at revealing the regularities of the effect of annealing temperature on the change in the structural and morphological properties of nanoparticles $[25,26]$. In turn, the developed technique of obtaining ferrite nanoparticles with controlled phase composition, morphology, and crystal structure can be further applied to the industrial production of absorbents for water purification. It is known that in recent years, the problem of wastewater pollution by various chemical reagents, organic dyes, or heavy metals is becoming more and more critical. The accumulation of pollutants in water can cause catastrophic consequences associated with poisoning of the environment and living organisms, mutations, etc. In most cases, pollutants cannot be neutralized by traditional methods, due to their high chemical inertness and resistance to decomposition, which requires finding new ways of their utilization without being energy- and resource intensive. One of such methods is the method of pollutant absorption on the surface of nanoparticles with their subsequent neutralization and utilization [27-30]. This method is very effective and energy saving, and the magnetic properties of nanoparticles allow their use for several cycles without mass loss.

Based on the above, the purpose of this work is to evaluate the application of $\mathrm{NiFe}_{2} \mathrm{O}_{4}$ nanoparticles with spinel structures as the basis of catalysts for the purification of aqueous media from pollutants such as manganese and arsenic.

\section{Results and Discussion}

\subsection{Influence of Annealing Temperature on Structural Properties and Degree of Ordering of $\mathrm{NiFe}_{2} \mathrm{O}_{4}$ Nanoparticles}

Figure 1a shows the results of changes in the morphological features of the synthesized nanoparticles depending on the annealing temperature. For comparison, an image of the initial powder obtained after synthesis and not subjected to thermal treatment is shown. As can be seen from the presented data, a change in the annealing temperature leads to a change in the morphological features of nanoparticles related primarily to their enlargement and formation of large agglomerates at high temperatures (above $700{ }^{\circ} \mathrm{C}$ ) resulting from the sintering of nanoparticles. It should be noted that the main morphological changes occur at temperatures above $400{ }^{\circ} \mathrm{C}$, when a slight change in the shape of particles close to spherical 
is observed. At temperatures above $500{ }^{\circ} \mathrm{C}$, partial enlargement of particles is observed, with the formation of an insignificant number of large particles, the size of which is more than $40-50 \mathrm{~nm}$. Meanwhile, an increase in annealing temperature leads to an increase in the number of large particles, and at temperatures of $900-1000{ }^{\circ} \mathrm{C}$, dendrite-like formations of large size consisting of grains larger than $50 \mathrm{~nm}$ are observed. Such morphological changes at temperatures above $700{ }^{\circ} \mathrm{C}$ are due to the sintering processes of grains, followed by the formation of large agglomerates. An increase in the grain size, in this case, is due to the sintering of nanoparticles, followed by the formation of large agglomerates. In turn, a change in the shape of nanoparticles with the formation of a dendritic structure is also due to agglomeration processes at high temperatures, caused by thermal effects leading to sticking and sintering of small grains into larger ones.
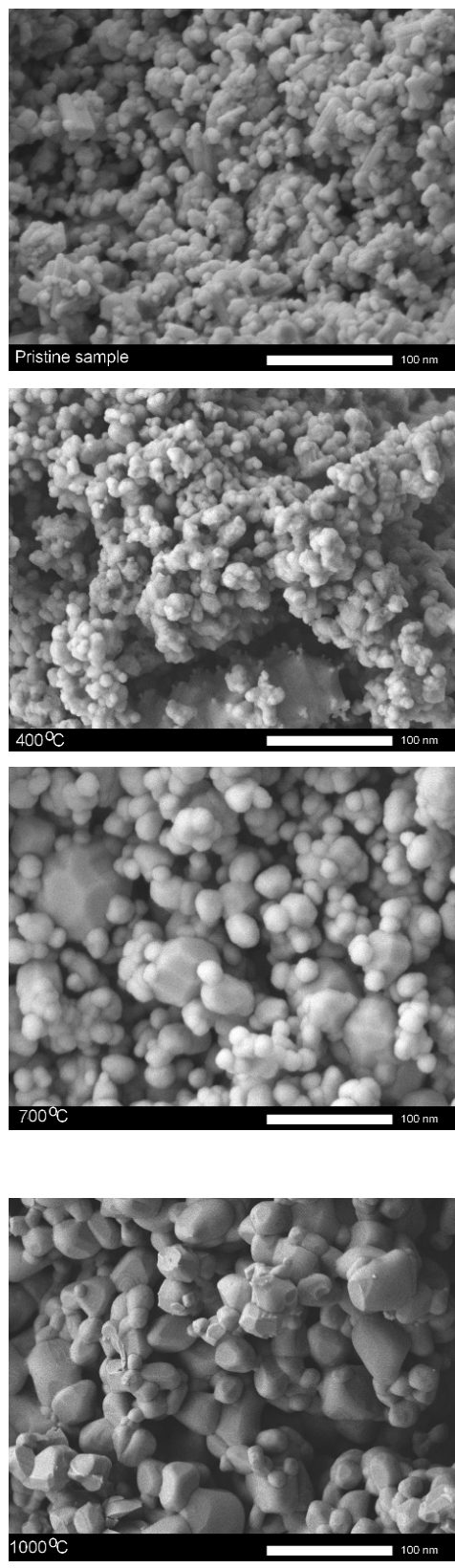

(a)
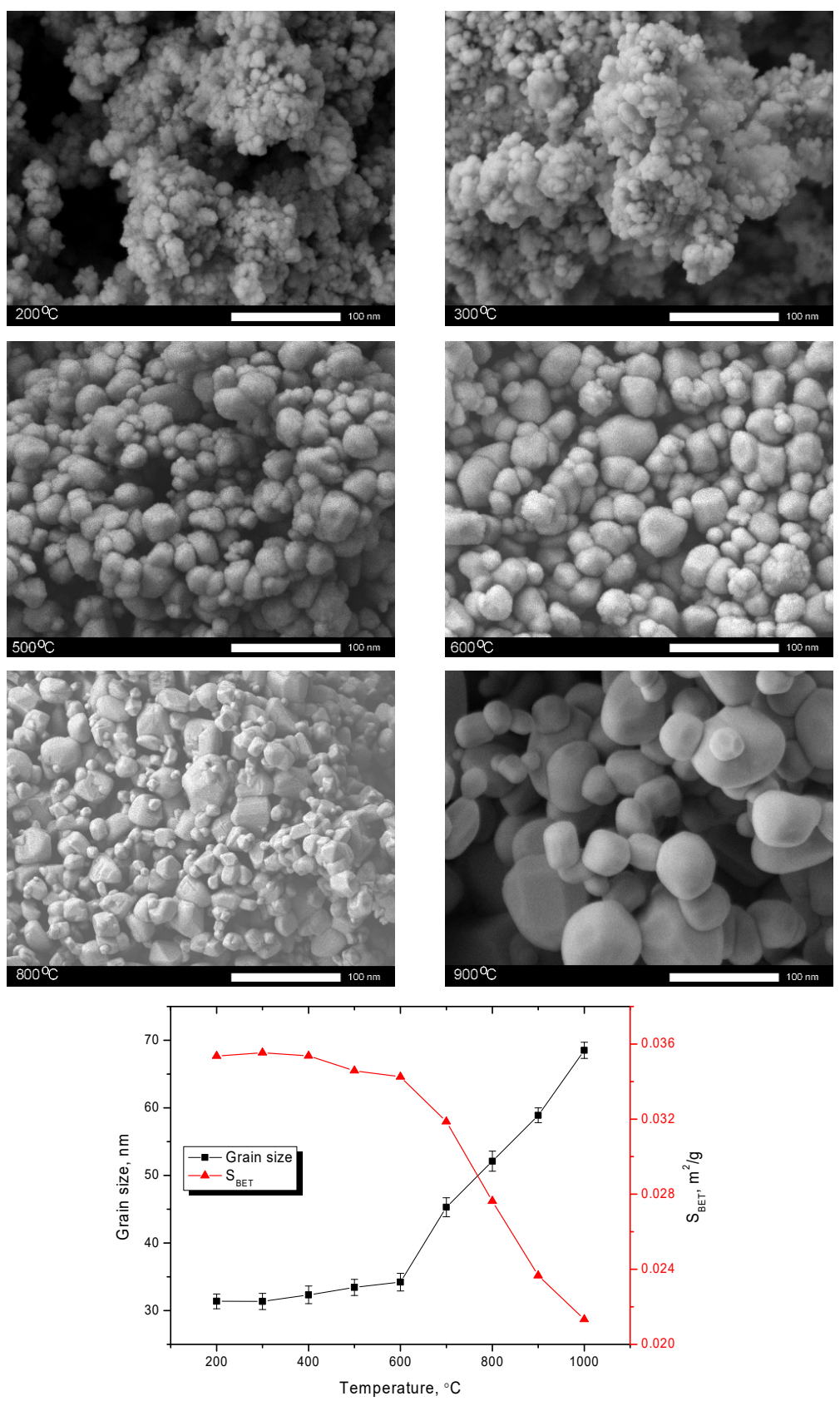

(b)

Figure 1. (a) SEM images of synthesized $\mathrm{NiFe}_{2} \mathrm{O}_{4}$ nanoparticles; (b) results of changes in grain size and specific surface area of $\mathrm{NiFe}_{2} \mathrm{O}_{4}$ nanoparticles. 
An increase in grain size, followed by the formation of agglomerates, leads to a decrease in the specific surface area (see Figure 1b), which may negatively affect the absorption characteristics of nanoparticles.

Table 1 presents the results of the effect of heat treatment on the change in the atomic ratio of the components in $\mathrm{NiFe}_{2} \mathrm{O}_{4}$ nanoparticles obtained by the analysis of the element distribution maps. The analysis of the obtained distribution maps revealed the presence of three components-oxygen, iron, and nickel—without the presence of any impurity elements.

Table 1. Results of energy-dispersive analysis.

\begin{tabular}{cccc}
\hline Temperature, ${ }^{\circ} \mathbf{C}$ & O, at. $\%$ & Fe, at. $\%$ & Ni, at. $\%$ \\
\hline 200 & $56.2 \pm 3.9$ & $26.7 \pm 3.2$ & $17.2 \pm 0.6$ \\
\hline 300 & $58.2 \pm 5.2$ & $25.4 \pm 4.5$ & $16.4 \pm 2.7$ \\
\hline 400 & $61.7 \pm 1.8$ & $23.0 \pm 0.4$ & $15.3 \pm 2.1$ \\
\hline 500 & $62.3 \pm 1.4$ & $22.0 \pm 1.0$ & $15.7 \pm 2.1$ \\
\hline 600 & $60.0 \pm 1.5$ & $23.3 \pm 1.0$ & $16.8 \pm 0.8$ \\
\hline 700 & $58.8 \pm 2.5$ & $27.2 \pm 1.3$ & $14.0 \pm 1.3$ \\
\hline 800 & $49.3 \pm 5.1$ & $32.2 \pm 3.7$ & $20.3 \pm 4.9$ \\
\hline 900 & $48.6 \pm 2.1$ & $30.5 \pm 2.4$ & $20.9 \pm 4.5$ \\
\hline 1000 & $45.5 \pm 4.7$ & $33.4 \pm 2.5$ & $21.2 \pm 2.5$ \\
\hline
\end{tabular}

From the data presented, it is clear that in the case of nanoparticles obtained at 200-600 ${ }^{\circ} \mathrm{C}$, there is a deviation from the stoichiometric formula $\mathrm{NiFe}_{2} \mathrm{O}_{4}$, with a large excess of iron and lack of oxygen. Increasing the annealing temperature leads to filling the vacancy positions with oxygen, followed by an increase in the oxygen content in the structure. According to the presented data of elemental analysis, for samples annealed at $700{ }^{\circ} \mathrm{C}$, the atomic ratio is close to $1: 2: 4$, which corresponds to the stoichiometric formula for nickel ferrite and proves the creation of nanoparticles with a composition of oxygen. However, a further increase in annealing temperature leads to oxygen displacement from the structure, which leads to a decrease in its concentration within nanoparticles. The displacement of oxygen may also be due to the agglomeration of grains into larger particles.

Figure 2 shows the X-ray diffractograms of the studied samples depending on the annealing temperature. An X-ray diffractogram of the samples after obtaining without heat treatment is shown as a sample comparison. This spectrum is presented for comparison in order to reflect the absence of an ordered structure of nanoparticles in the initial state without the effect of thermal annealing. In most studies [17-24] devoted to the synthesis of analogous systems in the initial state, nanoparticles are either highly disordered structures or close to amorphous structures.

According to the presented data, we can infer that in the case of samples not subjected to thermal annealing, there are no diffraction reflexes on the diffractogram, which indicates the absence of ordered crystal structure of the samples. In the case of thermal annealing at $200{ }^{\circ} \mathrm{C}$, the formation of low-intensity reflexes whose position corresponds to cubic $\mathrm{NFe}_{2} \mathrm{O}_{4}$ phase of Fd-3m (227) space syngony with spinel structure (PDF-00-066-0245) is observed. The $\mathrm{NiFe}_{2} \mathrm{O}_{4}$ compound is known to represent an inverse spinel structure in which the divalent and half of the trivalent ions are arranged in the octahedral positions and the remaining trivalent ions fill the tetrahedral positions. An increase in temperature above the annealing temperature of $400{ }^{\circ} \mathrm{C}$ leads to an increase in the intensity of these reflexes, which indicates an ordering of the crystal structure. It should be noted that unlike iron oxide nanoparticles, for which phase transformations of the magnetite-hematite type are observed at temperatures above $600^{\circ} \mathrm{C}$. In the case of iron-nickel oxide nanoparticles, no new reflexes are observed in the whole investigated temperature range of annealing, which indicates the absence of phase transformation processes. All basic changes observed 
on the X-ray diffractograms depending on temperature are connected with changes in the form of reflexes and their intensity, which indicates the ordering of structure due to change in dislocation density and reduction in deformations and distortions of the crystal lattice. In this case, for the annealing temperatures above $800^{\circ} \mathrm{C}$, a slight decrease in the reflection intensity and their shift to the region of small angles is observed, which is characteristic of the deformation of the interplanar distances and the broadening of the crystal lattice.

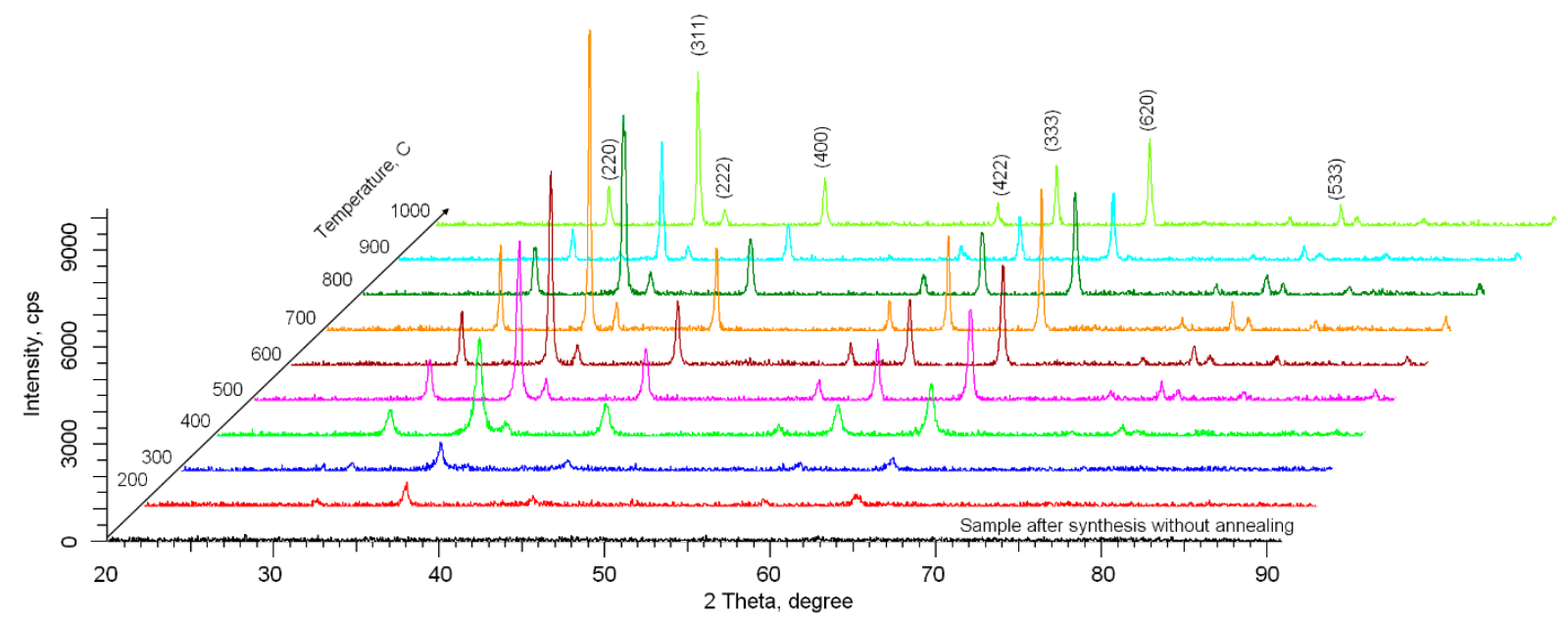

Figure 2. X-ray diffractograms of synthesized $\mathrm{NiFe}_{2} \mathrm{O}_{4}$ nanoparticles as a function of annealing temperature.

The dynamics of changes in the crystal lattice parameters and lattice volume presented in Figure 3a show the two-stage character of changes in the structural parameters. The first stage is characterized by a decrease in the values of the crystal lattice parameter, and, as a consequence, the volume of the crystal lattice, which indicates an ordering of the structure and a decrease in deformations. This behavior is due to the relaxation processes of metastable point defects that arose during synthesis, which annihilate as a result of external influences. Such behavior of point defects leads to a decrease in distorting stresses in the crystal lattice, which leads to its ordering. The rate of change in the crystal lattice parameters for different temperature intervals is different, indicating that at low annealing temperatures, most of the metastable defects annihilate, while increasing the temperature leads to the ordering of structure by filling the vacancy positions in the lattice with the subsequent formation of a highly ordered spinel structure. However, at annealing temperatures above $800{ }^{\circ} \mathrm{C}$, an increase in the crystal lattice parameters and its volume is observed, which indicates the occurrence of additional distortions and structural deformations. Such behavior of the parameters may be due to the processes of agglomeration of nanoparticles into larger structures, as well as partial displacement of oxygen from the positions in the sublattices.

Changes in the crystal lattice parameters, as well as the crystal's volume, directly affect the density of nanoparticles and the presence of porous inclusions in the structure. Figure $3 \mathrm{~b}$ shows the results of changes in the values of density and integral porosity, which were calculated on the basis of these changes in the crystal lattice volume. As can be seen from the presented data, the ordering of the crystal structure leads to an increase in the density of nanoparticles and a decrease in the value of integral porosity, which was estimated by the change in the density ratio of nanoparticles in the initial and annealed state. The nanoparticles agglomeration at high temperatures leads to the density decrease due to the structure deformation and the integral porosity increase. 


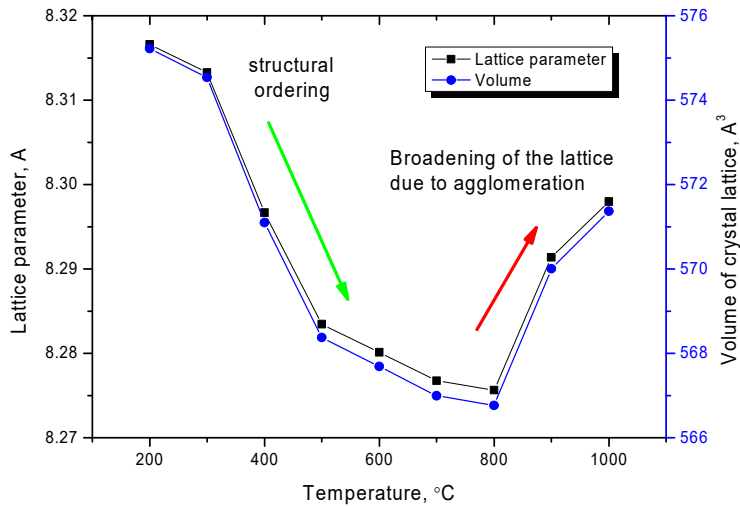

(a)

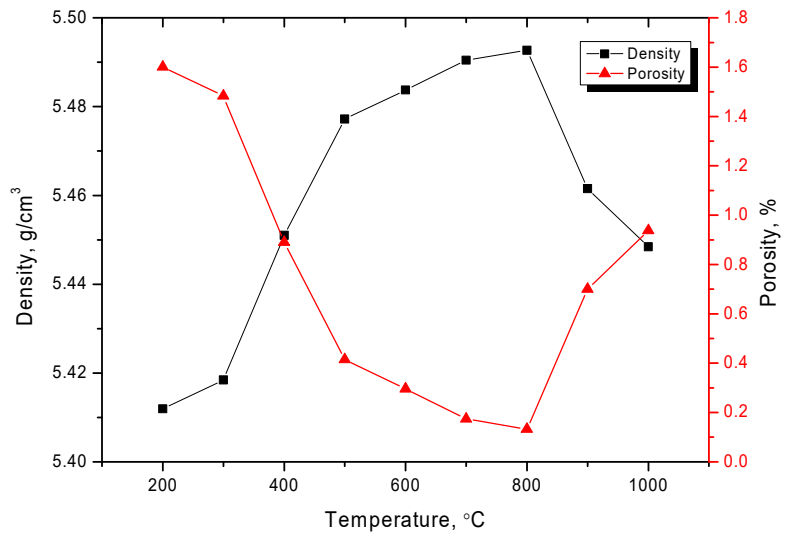

(b)

Figure 3. (a) Diagram of lattice structural parameters of $\mathrm{NiFe}_{2} \mathrm{O}_{4}$ nanoparticles as a function of annealing temperature; (b) diagram of nanoparticle density and integral porosity.

\subsection{Study of the Absorption Efficiency and Catalytic Properties of $\mathrm{NiFe}_{2} \mathrm{O}_{4}$ Nanoparticles}

Figure 4 shows the results of changes in the value of the optical density of manganese and arsenic solutions with catalysts based on $\mathrm{NiFe}_{2} \mathrm{O}_{4}$ nanoparticles placed in them. As can be seen from the presented data on the changes in optical density, the graph can be divided into three different sections corresponding to different values of the optical density reduction efficiency. The first plot is characteristic of the samples obtained at temperatures of $200-400{ }^{\circ} \mathrm{C}$. In this case, the decrease in optical density is less than 2 times for the samples obtained at $300-400{ }^{\circ} \mathrm{C}$, and practically, there is no change of optical density for the samples obtained at $200{ }^{\circ} \mathrm{C}$.

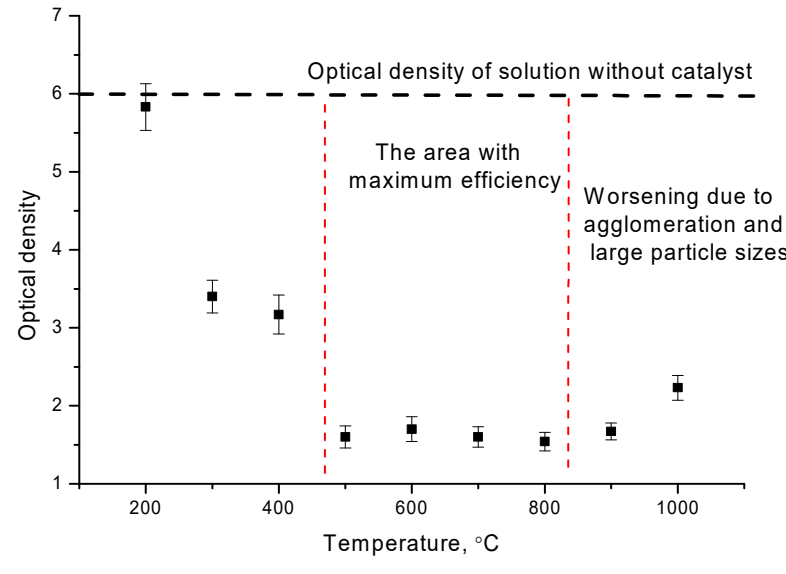

(a)

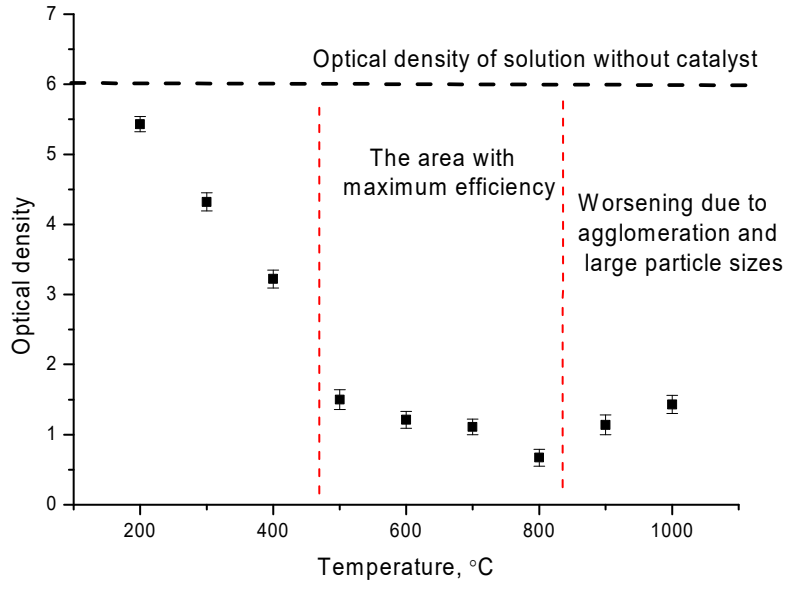

(b)

Figure 4. Diagram of the change in the optical density of the solution depending on the type of catalyst (the black dotted line indicates the optical density of the solution without a catalyst: (a) in the case of manganese absorption; (b) in the case of arsenic absorption.

The second region is characterized by annealing temperatures of $500-800{ }^{\circ} \mathrm{C}$ nanoparticles and is characterized by an optical density value of 1.4-1.6, which is 4 times lower than the initial value in the case of manganese absorption. For the absorption of arsenic, the decrease in optical density is more evident and is $0.7-1.1$, which is more than 5 times lower than the initial value.

The third region is characteristic of temperatures above $800^{\circ} \mathrm{C}$ and is characterized by a slight deterioration in the change in optical density, indicating a decrease in the 
efficiency of manganese absorption. This behavior may be due to the agglomeration of nanoparticles and an increase in their size, which leads to a decrease in the active surface area involved in absorption. Reduction in the specific surface area, as well as the formation of agglomerates, leads to the complication of metal ions absorption processes on the surface of the nanoparticles, which leads to the deterioration of purification efficiency.

Figure 5 shows the absorption efficiency diagram, which characterizes the degree of purification of aqueous solutions from pollutants. As can be seen from the data presented, the maximum purification efficiency for manganese is more than $70 \%$ for nanoparticles obtained at annealing temperature $500-800{ }^{\circ} \mathrm{C}$, while increasing the annealing temperature above $800{ }^{\circ} \mathrm{C}$ leads to a deterioration in efficiency by $3-10 \%$. Simultaneously, the absorption efficiency and the degree of purification from arsenic are much higher, and the maximum degree of purification is more than $85 \%$.

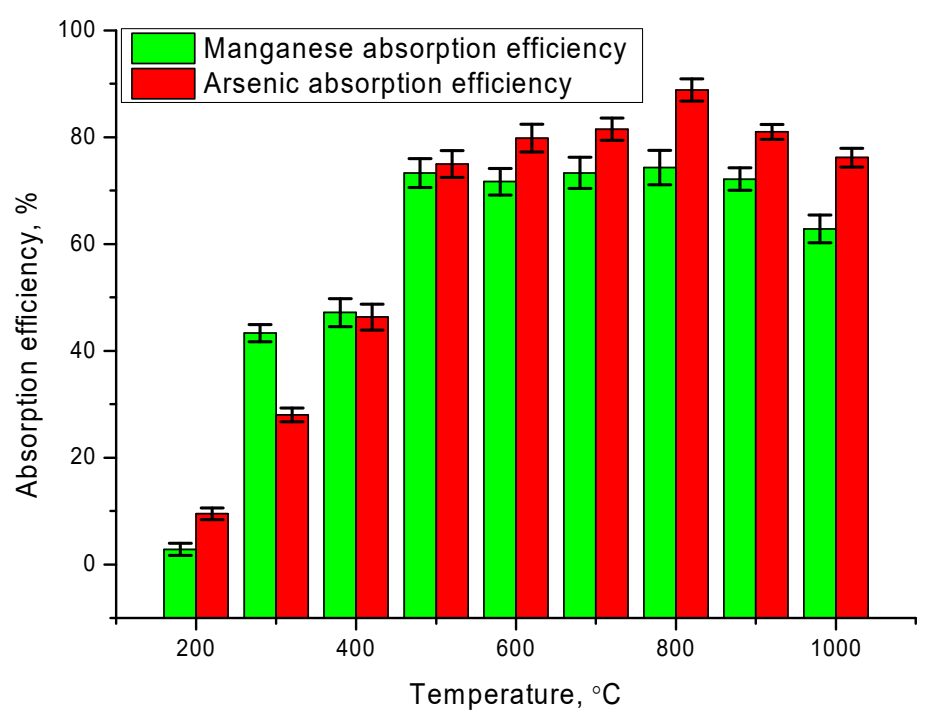

Figure 5. Absorption efficiency diagram of manganese and arsenic from aqueous solutions.

It should be noted that the decrease in the absorption efficiency of nanoparticles obtained at an annealing temperature above $800{ }^{\circ} \mathrm{C}$ is associated primarily with a change in the specific surface area involved in the absorption process, as well as a change in the structural and morphological properties of nanoparticles.

Figure 6 shows the results of changes in the morphological characteristics of nanoparticles obtained at a temperature of $700{ }^{\circ} \mathrm{C}$ after the absorption cycle, according to which growths are formed on the surface of nanoparticles, with a size of 3-5 nm. Analysis of the elemental composition of these growths showed that they contain manganese and arsenic, depending on the type of absorption reaction in which the nanoparticles were involved. However, the concentrations of these elements do not exceed 2-3 at.\%. Hence, from the obtained data, we can conclude that the main cleaning mechanism is associated with the absorption of manganese ions or arsenic on the surface of the nanoparticles, through the formation of complex compounds and the formation of small inclusions. 


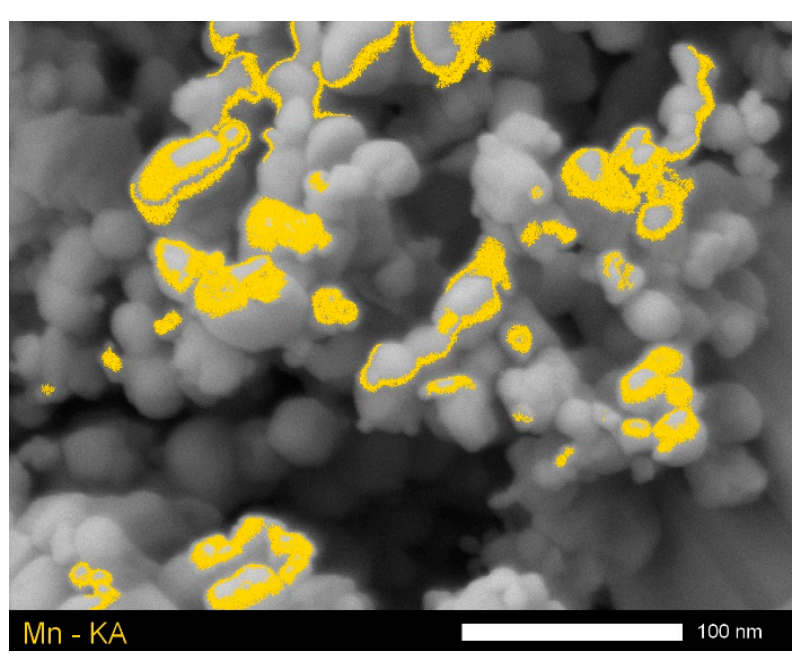

(a)

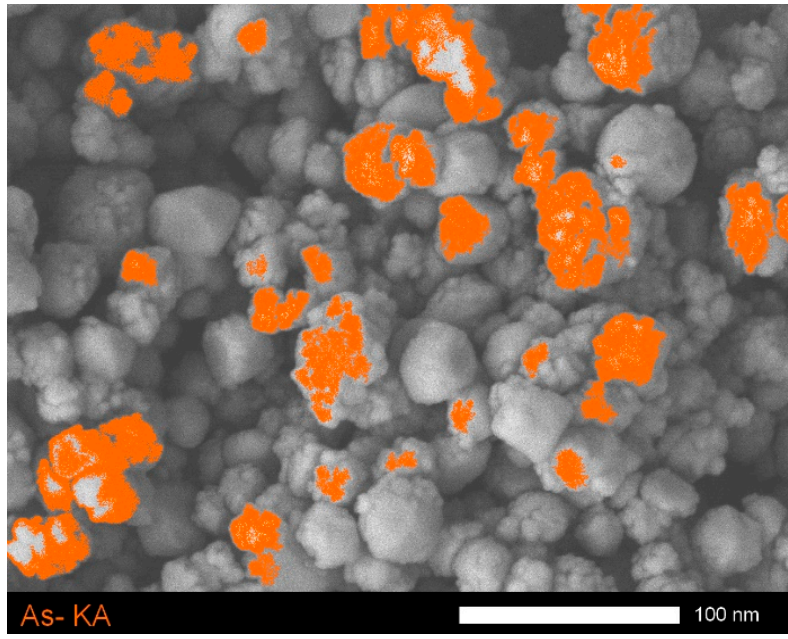

(b)

Figure 6. SEM images with maps of distribution of absorbed contaminants: (a) after manganese absorption; (b) after arsenic absorption.

One of the important parameters of nanoparticles' efficiency as catalysts is the preservation of the absorption efficiency during several consecutive cycles. According to the data obtained, $\mathrm{NiFe}_{2} \mathrm{O}_{4}$ nanoparticles obtained at annealing temperature $700{ }^{\circ} \mathrm{C}$ have the highest purification efficiency, for which the degree of purification was more than $77 \%$ and $85 \%$ of manganese and arsenic, respectively. Figure 7 a shows the results of cyclic tests of these nanoparticles, conducted through five consecutive cycles of absorption and evaluation of the purification efficiency after each cycle. As can be seen from the data presented, after five cycles, the purification efficiency for the selected nanoparticles decreases insignificantly, and the difference between cycles 1 and 5 is not more than $2-4 \%$, which confirms the stability and resistance of nanoparticles during long-term operation, while in the case of arsenic absorption, the purification efficiency is practically unchanged over 4 cycles. This preservation of purification efficiency during long-term operation is due to a high degree of ordering of structural properties of nanoparticles, as well as a high specific surface area, which contributes to the absorption processes with the subsequent formation of complexes.

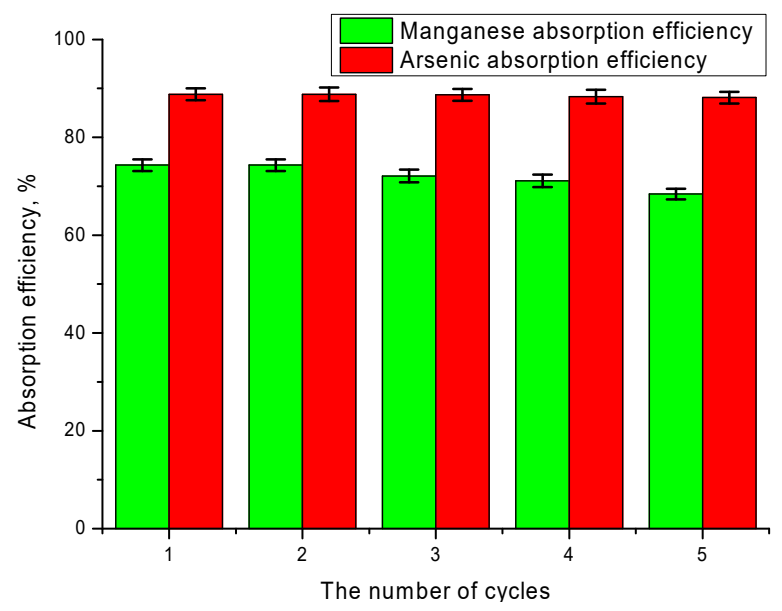

(a)

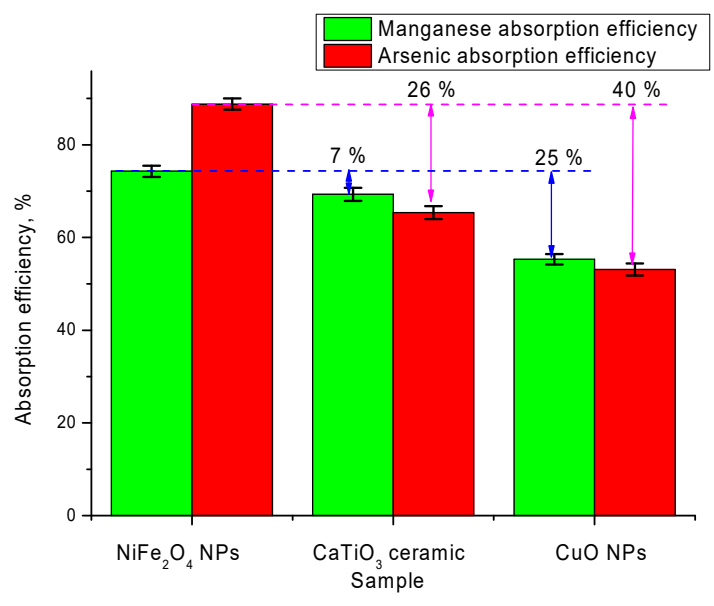

(b)

Figure 7. (a) Absorption efficiency diagram during five cycles; (b) comparative absorption efficiency diagram of synthesized nanoparticles with commercial analogs. 
To evaluate the effectiveness of the synthesized nanoparticles as a basis for catalysts in comparison with commercial analogs, a comparative experiment on the purification of aqueous media from manganese and arsenic using nanostructured ceramics $\mathrm{CaTiO}_{3}[31,32]$ and $\mathrm{CuO}$ nanoparticles (CuO NPs) [33,34] was performed. The choice of these types of structures for comparison is due to the fact that they are used as the basis of most catalysts for the purification of aqueous media from various types of pollutants, including heavy metals. For comparative analysis, $\mathrm{NiFe}_{2} \mathrm{O}_{4}$ nanoparticles obtained at an annealing temperature of $700{ }^{\circ} \mathrm{C}$ were chosen, which showed the best absorption results. The results of the comparative analysis are shown in Figure $7 \mathrm{~b}$. As can be seen from the data presented, the $\mathrm{NiFe}_{2} \mathrm{O}_{4}$ nanoparticles obtained in the work have high efficiency, compared with the selected commercial analogs. In this case, $\mathrm{NiFe}_{2} \mathrm{O}_{4}$ nanoparticles have the highest efficiency in the absorption of arsenic, for which the absorption efficiency exceeds the commercial analogs by $25-40 \%$.

\section{Materials and Research Methods}

Nickel ferrite nanoparticles were prepared by sol-gel method with ethylenediaminetetraacetic acid (EDTA), as a complexing agent, to produce nanoparticles and subsequent annealing in a muffle furnace. Solutions $\mathrm{A}, \mathrm{B}$, and $\mathrm{C}$ were prepared for this purpose. To prepare solution $\mathrm{A}$, an analytical suspension of 0.1 moles of $\mathrm{Ni}\left(\mathrm{NO}_{3}\right)_{2} \cdot 6 \mathrm{H}_{2} \mathrm{O}$ and 0.2 moles of $\mathrm{Fe}\left(\mathrm{NO}_{3}\right)_{3} \cdot 9 \mathrm{H}_{2} \mathrm{O}$ was dissolved in deionized water. Solution B consisted of 3.0 moles of citric acid dissolved in deionized water. Dissolving 0.3 moles of EDTA produced solution $\mathrm{C}$. The solutions were combined by adjusting $\mathrm{pH}$ with ammonia and raising it to 7 . The resulting mixture was stirred continuously at $\mathrm{t}=60^{\circ} \mathrm{C}$ for several hours, gradually increasing the temperature to $100{ }^{\circ} \mathrm{C}$. As soon as the color and viscosity of the solution changed, stirring was stopped and the temperature was increased to $180^{\circ} \mathrm{C}$, until complete dehydration. As a result of the reaction, the resulting gel was self-igniting and combusted to form a loose black powder.

To remove impurities, increase phase purity and crystallinity, and study the effect of temperature on the structural properties of the samples, thermal annealing was carried out in a muffle furnace $4 / 11$ /SKM Nabertherm (Germany) in an oxygen-containing medium in the temperature range of $200-1000{ }^{\circ} \mathrm{C}$. The furnace heating rate was $20^{\circ} \mathrm{C} / \mathrm{min}$, and after the furnace temperature was stabilized to the selected temperature, the samples were annealed for $5 \mathrm{~h}$, followed by cooling of the samples together with the furnace for $24 \mathrm{~h}$. After annealing, the samples were placed in sealed containers to avoid airborne degradation and aging processes associated with oxidation. These conditions of annealing and subsequent cooling of the samples, together with the furnace, make it possible to avoid stress conditions caused by a sharp temperature drop and subsequent oxidation processes.

The morphological features of the synthesized nanoparticles depending on the annealing temperature conditions were analyzed by analyzing the images obtained on a Jeol JSM-7500F scanning electron microscope (Jeol, Japan).

The elemental composition was investigated using the energy-dispersive analysis method implemented using a Hitachi TM3030 scanning electron microscope (Hitachi, Japan). Determination of the elemental ratio was performed by analyzing the obtained element distribution maps and collecting statistical data with subsequent averaging and determining the error of measurements.

The structural parameters were determined using the X-ray diffraction method. A powder X-ray diffractometer D8 Advance ECO (Bruker, Germany) was used to obtain diffractograms. Diffractograms were taken in Bragg-Brentano geometry in the range of angles $2 \theta=20-90^{\circ}$, with a step of $0.02^{\circ}$ and a spectrum acquisition time of 1 sec per point. The structural parameters were determined using the DiffracEVA v.4.2. software code, which is based on the full-profile analysis method based on the Rietveld method. The lattice parameters were refined by comparing the positions of the diffraction maxima of the main reflexes with the positions of the reference lines from the PDF-2(2016) database. The 
change in lattice volume, reflecting the degree of its ordering and affecting nanoparticle density, was evaluated by determining lattice parameters, followed by recalculation.

The density of nanoparticles was determined by the X-ray diffraction method by analyzing the obtained data on changes in structural parameters, including the crystal lattice volume.

The integral porosity value was determined by evaluating the ratio of changes in the density of nanoparticles in the initial and annealed state, depending on the annealing temperature.

The specific surface area of $S_{\mathrm{BET}}$ was estimated by the Brunauer-Emmett-Telleras adsorption method using a Gemini VII 2390 analyzer (Micromeritics, GA, USA). The calculations were performed using Equation (1) as follows:

$$
S_{\mathrm{BET}}=6 /\left(\rho_{\mathrm{X}} D_{\mathrm{BET}}\right)
$$

where $D_{\mathrm{BET}}$ is the grains' size; $\rho_{\mathrm{X}}$ is the material density determined by the $\mathrm{X}$-ray method.

To assess the effectiveness of purification of aqueous media from pollutants, we chose a method for determining the optical density of manganese and arsenic ions in a model solution before and after adsorption, according to the method for measuring the mass concentration of manganese and arsenic, in natural, drinking and wastewater samples by the photometric method. The choice of model media is due to the possibility of conducting experiments to determine the absorption efficiency of these elements from aqueous solutions. As is known, these elements belong to the class of environmental pollutants that can cause negative effects on living organisms. In this connection, in recent years, a large number of different methods have been developed for their utilization and protection from negative impacts on the environment.

The measuring method was based on obtaining in an alkaline environment complex compound of manganese with formaldoxime with subsequent measurement of optical density on a liquid analyzer "Fluorat-02". A small weight of nickel ferrite nanoparticles was placed in the model solutions. They were kept in the model solution for $5 \mathrm{~h}$, after which they were analyzed according to the standard method of optical density determination. The absorption value was determined by evaluating the change in the intensity of the absorption band characteristic of the selected compounds during the experiment and determining the measurement error by conducting experiments in five parallels.

\section{Conclusions}

The paper presents the results of the evaluation of thermal annealing application for ordering of structural characteristics and formation of stable spinel phase of $\mathrm{NiFe}_{2} \mathrm{O}_{4}$ in ferritic nanoparticles obtained by the sol-gel method. In the course of this research, it was found that highly ordered $\mathrm{NiFe}_{2} \mathrm{O}_{4}$ nanoparticles with an average size of $30-35 \mathrm{~nm}$ are formed at $500-700{ }^{\circ} \mathrm{C}$. During the evaluation of the absorption efficiency of synthesized nanoparticles for purification of aqueous media from manganese and arsenic, it was found that the nanoparticles obtained at an annealing temperature of $700{ }^{\circ} \mathrm{C}$ have the highest efficiency. A comparative analysis of the purification efficiency with commercial analogs showed that these structures are significantly better than commercial nanoparticles and nanostructured ceramics. In this regard, we can conclude that the proposed method of obtaining $\mathrm{NiFe}_{2} \mathrm{O}_{4}$ nanoparticles with their subsequent thermal treatment at $700{ }^{\circ} \mathrm{C}$ allows obtaining monodisperse nanoparticles with high efficiency of water purification, and the proposed technology can be scaled in semi-industrial and industrial production of these absorbents.

Author Contributions: Conceptualization, A.L.K., M.V.Z. and A.S.Z.; methodology, A.L.K., M.V.Z. and I.E.K.; formal analysis, R.S.A., M.V.Z., A.L.K.; investigation, A.L.K., A.S.Z. and M.V.Z.; resources, A.L.K.; writing—original draft preparation, review and editing, A.L.K. and M.V.Z.; visualization, A.L.K.; supervision, M.V.Z.; project administration, M.V.Z.; and funding acquisition, A.L.K. and M.V.Z. All authors have read and agreed to the published version of the manuscript. 
Funding: This research received no external funding.

Conflicts of Interest: The authors declare that they have no known competing financial interests or personal relationships that could have appeared to influence the work reported in this paper.

\section{References}

1. Bilal, M.; Rasheed, T.; Mehmood, S.; Tang, H.; Ferreira, L.F.R.; Bharagava, R.N.; Iqbal, H.M. Mitigation of environmentally-related hazardous pollutants from water matrices using nanostructured materials-A review. Chemosphere 2020, 253, 126770. [CrossRef] [PubMed]

2. Homocianu, M.; Pascariu, P. Electrospun polymer-inorganic nanostructured materials and their applications. Polym. Rev. 2020, 60, 493-541. [CrossRef]

3. Chen, X.; Liu, Q.; Bai, T.; Wang, W.; He, F.; Ye, M. Nickel and cobalt sulfide-based nanostructured materials for electrochemical energy storage devices. Chem. Eng. J. 2021, 409, 127237. [CrossRef]

4. Mironova-Ulmane, N.; Brik, M.; Grube, J.; Krieke, G.; Antuzevics, A.; Skvortsova, V.; Kemere, M.; Elsts, E.; Sarakovskis, A.; Piasecki, M.; et al. Spectroscopic studies of $\mathrm{Cr}^{3+}$ ions in natural single crystal of magnesium aluminate spinel $\mathrm{MgAl}_{2} \mathrm{O}_{4} \cdot \mathrm{Opt}_{\text {. }}$ Mater. 2021, 121, 111496. [CrossRef]

5. Mironova-Ulmane, N.; Popov, A.I.; Krieke, G.; Antuzevics, A.; Skvortsova, V.; Elsts, E.; Sarakovskis, A. Low-temperature studies of $\mathrm{Cr}^{3+}$ ions in natural and neutron-irradiated g-Al spinel. Low Temp. Phys. 2020, 46, 1154-1159. [CrossRef]

6. Lushchik, A.; Feldbach, E.; Kotomin, E.A.; Kudryavtseva, I.; Kuzovkov, V.N.; Popov, A.I.; Seeman, V.; Shablonin, E. Distinctive features of diffusion-controlled radiation defect recombination in stoichiometric magnesium aluminate spinel single crystals and transparent polycrystalline ceramics. Sci. Rep. 2020, 10, 1-9. [CrossRef]

7. Seeman, V.; Feldbach, E.; Kärner, T.; Maaroos, A.; Mironova-Ulmane, N.; Popov, A.; Shablonin, E.; Vasil'Chenko, E.; Lushchik, A. Fast-neutron-induced and as-grown structural defects in magnesium aluminate spinel crystals with different stoichiometry. Opt. Mater. 2019, 91, 42-49. [CrossRef]

8. Kadyrzhanov, K.K.; Egizbek, K.; Kozlovskiy, A.L.; Zdorovets, M. Synthesis and properties of ferrite-based nanoparticles. Nanomaterials. 2019, 9, 1079-1085. [CrossRef]

9. Kozlovskiy, A.L.; Egizbek, K.; Prmantayeva, B.A.; Zdorovets, M.V.; Kadyrzhanov, K.K. Effect of various dopants on structural properties of $\mathrm{A}_{\mathrm{x}} @ \mathrm{Fe}_{2-\mathrm{x}} \mathrm{O}_{3}(\mathrm{~A}=\mathrm{Nd}, \mathrm{Gd})$ nanocomposites. J. Mater. Sci. Mater. Electron. 2021, 32, 21670-21676. [CrossRef]

10. Kozlovskiy, A.L.; Egizbek, K.; Zdorovets, M.V.; Abdinov, R.S.; Kadyrzhanov, K.K. Study of structural features and phase transformations in nanocomposites of $\mathrm{Fe}_{2} \mathrm{O}_{3} @ \mathrm{NdFeO}_{3}$ type. J. Mater. Sci. Mater. Electron. 2021, 32, 21237-21247. [CrossRef]

11. Najjar, M.; Hosseini, H.A.; Masoudi, A.; Hashemzadeh, A.; Darroudi, M. Preparation of tin oxide (IV) nanoparticles by a green chemistry method and investigation of its role in the removal of organic dyes in water purification. Res. Chem. Intermed. 2020, 46, 2155-2168. [CrossRef]

12. Liu, J.; Chen, H.; Shi, X.; Nawar, S.; Werner, J.G.; Huang, G.; Ye, M.; Weitz, D.A.; Solovev, A.A.; Mei, Y. Hydrogel microcapsules with photocatalytic nanoparticles for removal of organic pollutants. Environ. Sci. Nano 2020, 7, 656-664. [CrossRef]

13. You, J.; Wang, L.; Zhao, Y.; Bao, W. A review of amino-functionalized magnetic nanoparticles for water treatment: Features and prospects. J. Clean. Prod. 2021, 281, 124668. [CrossRef]

14. Khan, F.S.A.; Mubarak, N.M.; Tan, Y.H.; Karri, R.R.; Khalid, M.; Walvekar, R.; Abdullah, E.C.; Mazari, S.A.; Nizamuddin, S. Magnetic nanoparticles incorporation into different substrates for dyes and heavy metals removal-A review. Environ. Sci. Pollut. Res. 2020, 27, 43526-43541. [CrossRef]

15. Rusakov, V.S.; Kadyzhanov, K.K.; Kozlovskiy, A.L.; Fadeev, M.S.; Zdorovets, M.V. Phase transformations as a result of thermal annealing of nanocomposite $\mathrm{Fe}-\mathrm{Ni} / \mathrm{Fe}-\mathrm{Ni}-\mathrm{O}$ particles. Ceram. Int. 2020, 46, 1586-1595. [CrossRef]

16. Maia, A.D.O.G.; Oliveira, F.G.S.; Cordeiro, C.H.N.; Teixeira, E.S.; da Silva, E.B.; Soares, J.M.; de Vasconcelos, I.F.; Sasaki, J.M.; Dumelow, T. Synthesis of $\mathrm{CoFe}_{2} \mathrm{O}_{4}$ superparamagnetic nanoparticles using a rapid thermal processing furnace with halogen lamps. J. Sol-Gel Sci. Technol. 2021, 99, 527-533. [CrossRef]

17. Jena, S.; Mishra, D.K.; Soam, A.; Jakhar, N.; Mallick, P. Control growth of $\mathrm{NiFe}_{2} \mathrm{O}_{4}$ phase in thermal annealed $\alpha-\mathrm{Fe}_{2} \mathrm{O}_{3} / \mathrm{NiFe}_{2} \mathrm{O}_{4}$ nanocomposites for the beneficial magnetic application. Appl. Phys. A 2021, 127, 1-18. [CrossRef]

18. Amulya, M.S.; Nagaswarupa, H.; Kumar, M.A.; Ravikumar, C.; Prashantha, S.; Kusuma, K. Sonochemical synthesis of $\mathrm{NiFe}_{2} \mathrm{O}_{4}$ nanoparticles: Characterization and their photocatalytic and electrochemical applications. Appl. Surf. Sci. Adv. 2020, 1, 100023. [CrossRef]

19. Kozlovskiy, A.; Egizbek, K.; Zdorovets, M.V.; Ibragimova, M.; Shumskaya, A.; Rogachev, A.A.; Kadyrzhanov, K. Evaluation of the Efficiency of Detection and Capture of Manganese in Aqueous Solutions of FeCeOx Nanocomposites Doped with $\mathrm{Nb}_{2} \mathrm{O}_{5}$. Sensors 2020, 20, 4851-4860. [CrossRef]

20. Divya, S.; Sivaprakash, P.; Raja, S.; Muthu, S.E.; Eed, E.M.; Arumugam, S.; Oh, T.H. Temperature-dependent dielectric and magnetic properties of $\mathrm{NiFe}_{2} \mathrm{O}_{4}$ nanoparticles. Appl. Nanosci. 2021, 1-10. [CrossRef]

21. Zhang, W.; Zhou, P.; Liu, W.; Wang, H.; Wang, X. Enhanced adsorption/extraction of five typical polycyclic aromatic hydrocarbons from meat samples using magnetic effervescent tablets composed of dicationic ionic liquids and $\mathrm{NiFe}_{2} \mathrm{O}_{4}$ nanoparticles. J. Mol. Liq. 2020, 315, 113682. [CrossRef] 
22. Pang, B.; Zhang, M.; Zhou, C.; Dong, H.; Ma, S.; Feng, J.; Chen, Y.; Yu, L.; Dong, L. Heterogeneous $\mathrm{FeNi}_{3} / \mathrm{NiFe}_{2} \mathrm{O}_{4}$ nanoparticles with modified graphene as electrocatalysts for high performance dye-sensitized solar cells. Chem. Eng. J. 2021, 405, 126944. [CrossRef]

23. Zhang, Y.; Zhang, W.; Yu, C.; Liu, Z.; Yu, X.; Meng, F. Synthesis, structure and supercapacitive behavior of spinel $\mathrm{NiFe}_{2} \mathrm{O}_{4}$ and $\mathrm{NiO} @ \mathrm{NiFe}_{2} \mathrm{O}_{4}$ nanoparticles. Ceram. Int. 2021, 47, 10063-10071. [CrossRef]

24. Bashir, A.K.H.; Matinise, N.; Sackey, J.; Kaviyarasu, K.; Madiba, I.G.; Kodseti, L.; Ezema, F.; Maaza, M. Investigation of electrochemical performance, optical and magnetic properties of $\mathrm{NiFe}_{2} \mathrm{O}_{4}$ nanoparticles prepared by a green chemistry method. Phys. E Low-Dimens. Syst. Nanostruct. 2020, 119, 114002. [CrossRef]

25. Egizbek, K.; Kozlovskiy, A.L.; Ludzik, K.; Zdorovets, M.V.; Korolkov, I.V.; Marcinia, B.; Jazdzewska, M.; Chudoba, D.; Nazarova, A.; Kontek, R. Stability and cytotoxicity study of $\mathrm{NiFe}_{2} \mathrm{O}_{4}$ nanocomposites synthesized by co-precipitation and subsequent thermal annealing. Ceram. Int. 2020, 46, 16548-16555. [CrossRef]

26. Zampiva, R.Y.S.; Kaufmann, C.G.; Venturini, J.; dos Santos, L.M.; Yamashita, G.H.; Viegas, A.D.C.; Anzanello, M.J.; Caten, C.T.; Bergmann, C.P.; Alves, A.K. Role of the fuel stoichiometry and post-treatment temperature on the spinel inversion and magnetic properties of $\mathrm{NiFe} 2 \mathrm{O} 4$ nanoparticles produced by solution combustion synthesis. Mater. Res. Bull. 2021, 138, 111238. [CrossRef]

27. Zeng, H.; Zhai, L.; Qiao, T.; Yu, Y.; Zhang, J.; Li, D. Efficient removal of As(V) from aqueous media by magnetic nanoparticles prepared with Iron-containing water treatment residuals. Sci. Rep. 2020, 10, 1-12. [CrossRef]

28. Martinez-Boubeta, C.; Simeonidis, K. Magnetic nanoparticles for water purification. In Nanoscale Materials in Water Purification; Elsevier: Amsterdam, The Netherlands, 2019; pp. 521-552.

29. Benedé, J.L.; Chisvert, A.; Giokas, D.L.; Salvador, A. Development of stir bar sorptive-dispersive microextraction mediated by magnetic nanoparticles and its analytical application to the determination of hydrophobic organic compounds in aqueous media. J. Chromatogr. A 2014, 1362, 25-33. [CrossRef]

30. Huang, X.; Schmucker, A.; Dyke, J.; Hall, S.M.; Retrum, J.; Stein, B.; Remmes, N.; Baxter, D.; Dragnea, B.; Bronstein, L.M. Magnetic nanoparticles with functional silanes: Evolution of well-defined shells from anhydride containing silane. J. Mater. Chem. 2009, 19, 4231-4239. [CrossRef]

31. Solís, R.R.; Bedia, J.; Rodríguez, J.J.; Belver, C. A review on alkaline earth metal titanates for applications in photocatalytic water purification. Chem. Eng. J. 2021, 409, 128110. [CrossRef]

32. Karakozov, B.K.; Kozlovskiy, A.L.; Janseitov, D.M.; Zdorovets, M.V. Solid-phase synthesis and study of the structural, optical, and photocatalytic properties of the $\mathrm{ATiO}_{3}, \mathrm{~A}=\mathrm{Ca}, \mathrm{Sr}, \mathrm{Ba}$ ceramic. J. Mater. Sci. Mater. Electron. 2021, 32, 24436-24445. [CrossRef]

33. Bushra, F.; Sharfllahi, S.; Rabia, A.; Saif, A.C. Preparation of functionalized CuO nanoparticles using Brassica rapa leave extract for water purification. Desalin. Water Treat. 2019, 164, 192-205.

34. Shaheen, M.; Kalwar, N.H.; Intisar, A.; Batool, Z.; Rasheed, S.; Kousar, R. Efficient surfactant modified copper oxide nanoparticles for solar light driven water purification. Opt. Mater. 2021, 122, 111688. [CrossRef] 